\title{
Strategic Alliances In The Financial Services And Chemical Industries
}

Charles J. Cante, (E-mail: CCante@iona.edu), Iona College

Vincent J. Calluzzo, (E-mail: Vcalluzzo@iona.edu), Iona College

Huldah A. Ryan, (E-mail: Hryan@iona.edu), Iona College

\begin{abstract}
The penetration and practice of strategic alliances and Total Quality Management in a goods industry (Chemical Industry) was compared to that for a service industry (Financial Services). The ingoing hypothesis that the Financial Services Industry and the Chemical Industry were similar as it relates to strategic alliances and TQM, based on the longevity of these concepts, was not fully supported. Clear industry similarities and differences were noted. For example, the penetration of TQM and strategic alliances was deeper in the Chemical Industry. This is thought to be the result of the earlier application of TQM and strategic alliances in goods industries. Company size, as measured by revenue, did not affect whether small or medium sized companies in either industry practiced TQM, engaged in strategic alliances or the number of strategic alliances that each had. The proportion of strategic alliance practitioners who also practiced $T Q M$ was statistically similar for both industries. Importantly, a high, and similar, proportion of strategic alliance participants in both industries achieved business growth. While those practitioners did achieve a reduction of the numbers of suppliers there is significant room for improvement in both industries. Strategic alliance performance met or exceeded expectations and alliance costs were on or below forecasts in both industries but the result was significantly better for the Financial Services industry in both instances. The lower outcomes for the Chemical Industry are most likely rooted in negative aspects of relationships with strategic alliance partners as suggested by the top 5 advantages and top 5 disadvantages responses. Significantly, a high proportion of strategic alliances will continue with most of these being with the current partner and a few with new partners. The Financial Services Industry outperforms the Chemical Industry on this measure.
\end{abstract}

It is recommended that firms in the Financial Services Industry closely examine the benefits that strategic alliances can yield, and then conduct pilot tests. On the other hand, firms in the Chemical Industry need to improve their relationships with potential partners in order to maximize the outcome of strategic alliances.

\section{INTRODUCTION}

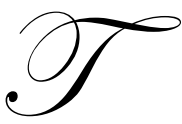

he past two decades have been characterized by an expansion of business through globalization, and the increased utilization of technology in achieving firm goals. In order to secure a competitive edge and survive in a global market environment, companies have realized the need to form cooperative arrangements, and pool their resources and skills to expand their capabilities. Strategic alliances are part of the Total Quality Management philosophy (TQM), which stresses, as one of its objectives, the need to achieve excellence in the marketplace. These corporate agreements have become a way of life for firms to gain access to new technologies, improve quality, reduce costs, expand market share, and increase profits. The growth of strategic alliances in both numbers and diversity of alliance areas is significant, because they can greatly impact business performance, in terms of new service offerings and product introductions, and can help to achieve strategic goals that are far beyond the reach of the single organization. 
The concept of the Strategic Alliance has been known since the 1980's. It is an element in the "Just-InTime" platform of Total Quality Management (TQM). Despite this longevity, the open literature does not abound with articles about these topics for specific industries. Rather, any information is of a general nature. Some research in strategic alliances has been published, but this has been limited to a few industries. These include the biomedical/healthcare industry - Yeheskel et al., 2001; Judge and Ryman, 2001; the technology industry - Cyr, 1999; and the food industry - Whipple and Frankel, 2000 and Cante et al., 2003. The Financial Services Industry and the Chemical Industry have participated in such alliances in ways that have not been well reported in the literature. Accordingly, the purpose of this study was to investigate strategic alliances that exist in the Financial Services and Chemical industries, two essential segments of the U.S. business environment.

The Financial Services firms examined are mainly drawn from the banking, real estate, and investment sectors. The industry is unique in that it is subject to government regulation, which can affect corporate strategies and opportunities that can be exploited. Historically, banks, brokerage houses, venture capitalists, real estate investment trusts, and other financial services providers have secured their niche in the industry and operated independently. However, fierce competition and the need to survive have forced firms to diversify and provide a 'supermarket' of services to their customers/clients through strategic alliances with partners who can provide the needed resources and skills. Because firms retain their independence, alliances can be formed or created, and discontinued, depending upon their success. In addition, the Financial Services Industry was of interest because of the significant consolidation of firms through acquisitions or mergers to obtain incremental client offerings with a broad array of products in lieu of, or in addition to, the use of strategic alliances.

In the Chemical Industry, companies can specialize in one or more of the following: manufacture, distribution, sales, marketing, or basic technical research in materials, products and processes. The Chemical Industry was selected for study because it is an important sector of the U.S. economy that impacts most goods industries and many service industries. This sector heavily depends on technical research and development (R\&D) for growth through new products, new processes, productivity and improved quality. The Chemical sector's results are affected by global competitors hence one would expect extensive use of strategic alliances with which to gain competitive advantages.

The choice of the Chemical Industry and the Financial Services Industry enables the authors to compare the penetration and usefulness of both strategic alliances and TQM in a goods vs. a service industry. This first study of these two industries would form a baseline of knowledge for each to be used to gauge growth, stagnation or decline over time. The intent is to re-examine these industries every 4 to 5 years.

\section{THEORETICAL BACKGROUND}

This study is based on three different approaches that explain inter-organizational strategic alliances. They include the transaction-cost theory, which proposes that firms develop strategic alliances to reduce costs, and this can lead to increased profits (Gulati, 1998); the strategic view, which suggests that firms pursue alliances to enjoy the benefits of economies of scale, risk reduction, and the expansion of firm resources associated with these collaborations (Powell, 1990); and the learning perspective, which proposes that firms enter into these alliances to gain access to specialized information (Dyer and Singh, 1998; Parise and Henderson, 2001).

\section{METHODOLOGY}

The research instrument was a 19-question survey similar to the one described by Cante et. al. (2003). The Financial Services Industry survey contained an additional three questions related to foreign alliances. The use of similar surveys that are industry specific allows one to make comparisons across industries regarding the responses to the questions and measures. The research was conducted in 2 mailings where the second pass was directed at those firms that did not respond to the first mailing within 90 days. 
The surveys were designed to investigate the following topics:

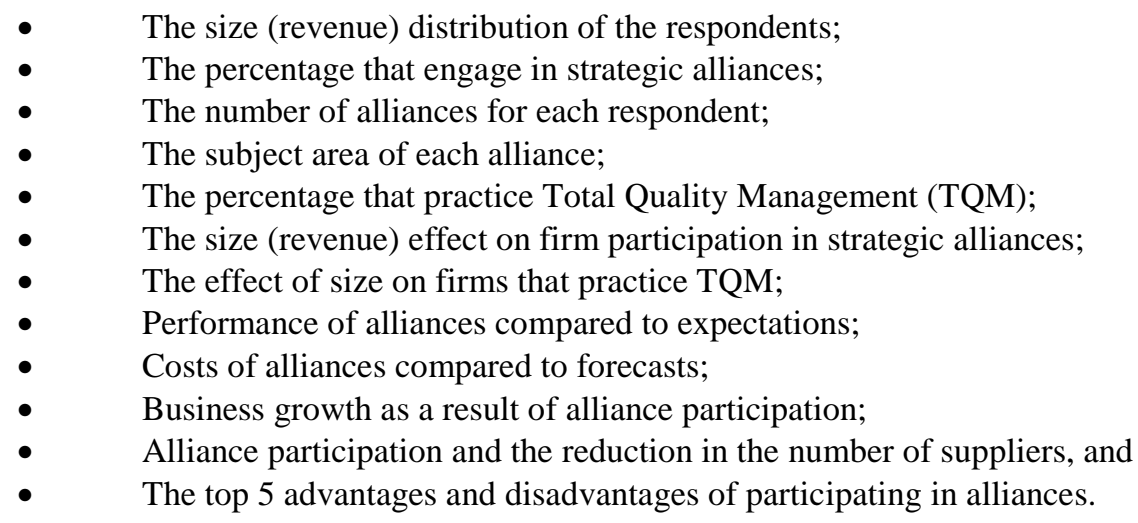

The primary sample, for the Financial Services firms, was initially compiled from the Forbes Magazine's annual compensation survey of the top 800 CEOs in the United States, for the years 2000-2001. The sampling procedure involves collecting data on the firms listed under the financial services section and then searching the Lexis/Nexis News Wire and Business Wire Databases for each firm's address and the name of its top executive. This process resulted in a final sample of 424 firms from the Financial Services Industry.

The Chemical Industry surveys were mailed to 237 firms of which 187 were members of the American Chemistry Council (formerly the Chemical Manufacturers Association) and all of the 75 companies in Chemical \& Engineering News' "Movers and Shakers" feature $(90 \%$ of the total population- the remaining $10 \%$ were either acquired, merged or liquidated/ dissolved or could not be located using the Thomas Registry or Dun \& Bradstreet's directory or "Anywho. Com").

The questionnaires were mailed with a personalized cover letter to the top executives (CEOs, Presidents, or Chief Operating Officers) of the publicly traded firms that are listed in the databases described above. The cover letter explained the purpose of the study and assured respondents of anonymity and the confidentiality of their responses.

The study hypothesis was that both industries should be comparable on all measures regarding strategic alliances and TQM given the longevity of both concepts.

Therefore, the responses of each industry were evaluated using Student's t-test and the Chi-square methods, as applicable, at the 0.05 level against the hypothesis of "no difference".

Table 1. Size (Revenue) Distribution of Respondents

\begin{tabular}{|l|c|c|}
\hline \multicolumn{1}{|c|}{ Revenue } & Financial Services & Chemicals \\
\hline$<\$ 100$ Million & $22.2 \%$ & $35.3 \%$ \\
\hline \$100-\$249 Million & $38.8 \%$ & $11.8 \%$ \\
\hline \$250-\$499 Million & $11.1 \%$ & $11.8 \%$ \\
\hline \$500-\$749 Million & $22.2 \%$ & $0 \%$ \\
\hline \$750-\$999 Million & $5.7 \%$ & $11.8 \%$ \\
\hline \$1-\$2.49 Billion & $0 \%$ & $11.8 \%$ \\
\hline \$2.5-\$4.99 Billion & $0 \%$ & $11.8 \%$ \\
\hline \$5-\$10 Billion & $0 \%$ & $0 \%$ \\
\hline$>\$ 10$ Billion & $0 \%$ & $5.7 \%$ \\
\hline
\end{tabular}

\section{RESULTS AND DISCUSSION}

The size distribution of the respondents in terms of revenue, shown in table 1, was good except for the absence of any response from the truly "mega" financial services companies. The revenue range of the industries was segmented into small ( $<\$ 100$ million), medium (\$100-\$999 million) and large ( $>\$ 1$ billion) to facilitate the presentation and discussion of the rest of the information.

The results indicate that $33 \%$ of Financial Services firms and $53 \%$ of Chemical firms engage in strategic alliances, while $44 \%$ of the former and $88 \%$ of the latter practice TQM. Both of these results are statistically different (t-test, 0.05). Clearly, the Chemical Industry leads the Financial Services Industry, although both need to grow in the employment of strategic alliances and the practice of TQM for competitive advantages. 
The differences between industries may reflect the earlier, and more intuitive, introduction of TQM and strategic alliances in the goods industries rather than some other problem.

Table 2. Does Size (Revenue) Affect Participating in Alliances?

\begin{tabular}{|l|c|c|c|}
\hline \multicolumn{1}{|c|}{ Size (revenue) } & \% Participating in Alliances & \% Participating in Alliances & Are these different? \\
\hline & Financial Services & Chemical & t-test at 0.05 \\
\hline Small $(<\$ 100$ Million) & $25 \%$ & $50 \%$ & No \\
\hline Medium $(\$ 100-\$ 999$ Million) & $35.7 \%$ & $50 \%$ & No \\
\hline Large $(>\$ 1$ Billion) & No data & $60 \%$ & Insufficient data \\
\hline
\end{tabular}

Table 3. Types of alliance service

\begin{tabular}{|l|c|}
\hline \multicolumn{1}{|c|}{ Type of service } & \% of Alliances \\
\hline Retail Banking & \\
\hline Commercial Banking & \\
\hline Investment Banking & \\
\hline Virtual Banking & \\
\hline Basic Technical Research & 9 \\
\hline Information Technology & 9 \\
\hline Distribution Technology & \\
\hline Debt Servicing & \\
\hline Marketing & \\
\hline Market Research & \\
\hline Check Processing & \\
\hline Risk Management & \\
\hline Fraud Detection & \\
\hline Supply Chain Management & \\
\hline Quality Management & \\
\hline Credit Checks & \\
\hline Human Resources & \\
\hline Asset Management & \\
\hline Mortgage Banking & 18 \\
\hline Mortgage Services & 18 \\
\hline Investment Management & 18 \\
\hline Insurance & \\
\hline
\end{tabular}

It was originally thought that size might affect participation in strategic alliances, the number of alliances and the practice of TQM, given the anecdotes that "it will take too many resources" to do so. As shown in table 2, size, as measured by revenue, does not appear to affect whether or not small or medium Financial Services or Chemical firms will participate in strategic alliances (no difference, t-test, 0.05). A comparison could not be made for large firms because of the lack of Financial Services large-firm responses. On the other hand, large Chemical firms were comparable to small and medium Chemical firms in that size was not an impediment. Also, size did not affect the number of alliances that either a Financial Services or Chemical firm would execute (no difference, Chisquare test) with the same caveat as discussed above. Additionally, the practice of TQM did not appear to be affected by size since there were no industry-to-industry differences at equal size or across sizes (t-test, at 0.05). Finally, there were no differences between industry on the question of the percent of strategic alliances practitioners who also practice TQM specifically: $66.7 \%$ of Financial Services firms and $77.7 \%$ of Chemical firms (t-test, 0.05).

Although the Financial Services firms may have strategic alliances in over 21 types of services (table 3 ), the majority of alliances were in 7 services namely, 1) investment management (18\%), 2) mortgage banking (18\%), 3) mortgage services $(18 \%), 4)$ insurance $(18 \%), 5)$ information technology $(9 \%), 6)$ distribution technology $(9 \%)$, and 7) marketing (9\%). On the other hand, the Chemical firms have alliances in 6 types of services namely, 1) product technology $(33 \%), 2)$ process technology $(11 \%), 3)$ basic technical research $(11 \%), 4)$ quality $(11 \%), 5)$ information technology (22\%) and 6) supply chain management (11\%). The finding for the Financial Services Industry suggests that the need for alliances in many of the "types of services" has been reduced or eliminated by the acquisitions and mergers bringing these services to the new firm. On the other hand, the Chemical Industry service types represent fundamental, essential platforms for which a company can never have enough (or can never afford enough).

Are strategic alliances worth the effort? The respondents answered this in terms of business growth, reduction in the number of suppliers, performance against expectations and the ultimate costs compared to the ingoing forecasts.

The findings indicate that $100 \%$ of the Financial Services firms and $89 \%$ of Chemical firms engaging in strategic alliances experienced business growth as a result (no industry-to-industry difference, t-test, 0.05). Firms in both industries had comparable success in reducing the number of suppliers. As shown in table 4, both industries achieved good performance vs. expectations with $91 \%$ of Financial Services firms and 58.7\% of Chemical firms that 
Table 4. Performance vs. Expectations

\begin{tabular}{|l|c|c|}
\hline \multicolumn{1}{|c|}{ Rating } & Financial Services & Chemical \\
\hline Exceeded Expectations & $4.3 \%$ & $0 \%$ \\
\hline Met Expectations & $87.0 \%$ & $58.7 \%$ \\
\hline Marginally Met Expectations & $0 \%$ & $39.1 \%$ \\
\hline Missed Expectations & $8.7 \%$ & $2.2 \%$ \\
\hline$\%$ Met or Exceeded Expectations & $91.3 \%$ & $58.7 \%$ \\
\hline Are these different? & Yes, t-test at 0.05 & \\
\hline
\end{tabular}

Table 5. Alliance Cost vs. Forecasts

\begin{tabular}{|l|c|c|}
\hline \multicolumn{1}{|c|}{ Variance vs. Plan } & Financial Services & Chemical \\
\hline Significantly Higher (11+\%) & $4.4 \%$ & $0 \%$ \\
\hline Higher (+3 to +10\%) & $4.4 \%$ & $39.1 \%$ \\
\hline On Plan & $91.2 \%$ & $56.5 \%$ \\
\hline Lower (-3 to -10\%) & $0 \%$ & $4.4 \%$ \\
\hline Significantly Lower (-11-\%) & $0 \%$ & $0 \%$ \\
\hline On or Below Plan & $91.2 \%$ & $60.9 \%$ \\
\hline Are these different & Yes, t-test at 0.05 & \\
\hline
\end{tabular}

participated in strategic alliances reporting "meeting or exceeding expectations." The industries were different (t-test, 0.05). Also surprisingly, while both industries had success with the cost of strategic alliances vs. forecast there was a difference (table 5) with the Financial Services firms reporting $91.2 \%$ of alliances "on or below cost forecast" and the Chemical firms reporting $60.9 \%$. Some insight into the reason for the differences in "performance" and "cost" appear in the "top 5 disadvantages" to be discussed next.

The top 5 advantages and the top 5 disadvantages to strategic alliance participation are shown in tables 6 and 7. The advantages list demonstrates some of the outstanding benefits of strategic alliances, and while the items are not identical for the two industries there are similarities related to new products and increased business. Interestingly, the Financial Services list includes "relationships" as an advantage. In contrast the disadvantages list for the Chemical firms are, for the most part, "relationship" items but from a negative viewpoint. Also newsworthy, is that the Financial Services only had two disadvantages to offer. Perhaps these negative relationship issues are resulting in lower performance than expectation with the added consequence of higher costs than desired. Clearly, the Chemical Industry needs to work on these issues in order to maximize the value of strategic alliances.

What is the future for the current strategic alliances? How many will continue with either current partners or new partners and how many will be discontinued?

Table 6. Top 5 Advantages of Alliance Participation

Table 7. Top 5 Disadvantages of Alliance Participation

\begin{tabular}{|l|l|}
\hline \multicolumn{1}{|c|}{ Financial Services } & \multicolumn{1}{c|}{ Chemical } \\
\hline Reliability & Market Access \\
\hline Relationships & New Products \\
\hline Resources and Products & Access to R\&D, Technology \\
\hline Customer Focus & Faster Growth \\
\hline Increased Volume & Reduced Cost \\
\hline
\end{tabular}

\begin{tabular}{|l|l|}
\hline \multicolumn{1}{|c|}{ Financial Services } & \multicolumn{1}{c|}{ Chemical } \\
\hline Inability to Change Direction & Lack of Trust \\
\hline Low Performance & Lack of Focus by Partner \\
\hline & Insufficient Effort by Partner \\
\hline & Cultural Differences \\
\hline & Legal Aspects \\
\hline
\end{tabular}

All $23(100 \%)$ Financial Services strategic alliances will continue and do so with the current partner(s) whereas only $22(48 \%)$ of Chemical ones will continue and do so with current partners (statistically significant, Chisquared test, 0.05 ). In the case of the Chemical strategic alliances, $13 \%$ will be discontinued, $11 \%$ will continue, but with new partners, while the balance, $28 \%$, are too soon to judge.

\section{CONCLUSIONS AND RECOMMENDATIONS}

The ingoing hypothesis that the Financial Services Industry and the Chemical Industry were similar as it relates to strategic alliances and TQM was not fully supported. Clear industry similarities and differences were noted. 
First, the penetration of TQM and strategic alliances was deeper in the Chemical Industry. This is thought to be the result of the earlier application of TQM and strategic alliances in goods industries. However, there is room for growth in TQM and strategic alliances in both industries.

Second, size, as measured by revenue, did not affect whether small or medium sized companies in either industry, or large Chemical firms, practiced TQM, engaged in strategic alliances, or the number of strategic alliances that each had. The proportion of strategic alliance practitioners who also practiced TQM was statistically similar for both industries.

Third, a high, and similar, proportion of strategic alliance participants in both industries achieved business growth. While those practitioners did achieve a reduction of the numbers of suppliers there is significant room for improvement in both industries.

Fourth, performance met or exceeded expectations and alliance costs were on or below forecasts in both industries but the result was significantly better for the Financial Services Industry in both instances. The lower outcomes for the Chemical Industry are most likely rooted in negative aspects of relationships with strategic alliance partners as suggested by the top 5 advantages and top 5 disadvantages responses.

Fifth, a high proportion of strategic alliances will continue with most of these being with the current partner and a few with new partners. The Financial Services Industry outperforms the Chemical Industry on this measure.

Corporate alliances play an essential role in the success of business organizations because they enable firms to achieve firm objectives that would otherwise be unreachable. The Financial Services and Chemical industries have participated in these alliances, which can create opportunities for each partner. Accordingly, firms are increasingly placing added emphasis on corporate arrangements because they are useful tools by which they can acquire knowledge and resources; satisfy customer/client demand; and take advantage of an expanding global market environment.

It is recommended that firms in the Financial Services Industry closely examine the benefits that strategic alliances can yield, and then, each should conduct a pilot test. On the other hand, firms in the Chemical Industry need to improve their relationships with potential partners in order to maximize the outcome of strategic alliances.

\section{REFERENCES}

1. Cante, Charles J., Vincent J. Calluzzo and Huldah A. Ryan. May 2003. "Strategic Alliances In The Food And Beverage Industry. ” J. Business And Economic Research, 1, (5): 47-57.

2. Cyr, Dianne, 1999. "High Tech, High Impact: Creating Canada's Competitive Advantage through Technology Alliances", The Academy of Management Executive, 13 (2): 17-26.

3. Dyer, J., and H. Singh, 1998. "The Relational View: Cooperative Strategy and Sources of Interorganizational Competitive Advantage", Academy of Management Review, 23 (4) 666-679.

4. Gulati, R., 1988. "The Architecture of Cooperation: Managing Coordination Costs and Appropriation Concerns in Strategic Alliances", Administrative Science Quarterly, 43 (4): 781-814.

5. Judge, W. and J. Ryman, 2001. "The Shared Leadership Challenge of Strategic Alliances Lessons from the U.S. Healthcare Industry", The Academy of Management Executive, 15 (2): 71-79.

6. Kogut, B., 1988. "Joint Ventures: Theoretical and Empirical Perspectives", Strategic Management Journal, 9: 319-332.

7. Parise, S., and J. Henderson, 2001. "Knowledge Resource Exchange in Strategic Alliances", IBM Systems Journal, Armonk, 40 (4): 908-924.

8. Powell, W., 1990. "Neither Market Nor Hierarchy: Network Forms of Organization", in L.L. Cummings and B. Staw, Eds. Research in Organizational Behavior, 12 :295-336.

9. Yeheskel, O., Shenkar, O., Fiegenbaum, A., and E. Cohen, 2001. "Cooperative Wealth Creation: Strategic Alliances in Israel Medical-Technology Ventures", The Academy of Management Executive, 15 (1): 16-24. 